\title{
Female genital mutilation: what every paediatrician should know
}

\author{
Sarah M Creighton, Deborah Hodes
}

University College London Hospital, London, UK

\section{Correspondence to} Sarah Creighton, University College London Hospital, 250 Euston Road, London WC1 2PG, UK ;

sarah.creighton@uclh.nhs.uk

Received 23 January 2015 Accepted 24 February 2015 Published Online First 19 March 2015

\section{SLinked}

- http://dx.doi.org/10.1136/ archdischild-2015-308243

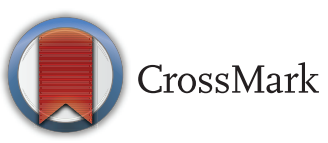

To cite: Creighton $\mathrm{SM}$ Hodes D. Arch Dis Child 2016;101:267-271.

\section{ABSTRACT}

Female genital mutilation (FGM) is almost always performed on children and consequently paediatricians should have a central role in the detection and prevention of FGM. FGM has no health benefits and can cause lifelong damage to physical and psychological health. Extensive migration of FGM practising communities means that FGM is now a global problem. Paediatricians worldwide need to be familiar with the identification and classification of FGM and its impact upon health as well as current trends in practice. However information about FGM is hampered by the secrecy surrounding the procedure and a lack of rigorous evidence based research. This review summarises what is currently known about the health aspects of FGM and how paediatricians should manage children with FGM in their clinical practice.

\section{INTRODUCTION}

Female genital mutilation (FGM) is defined by WHO as procedures which remove or damage the external female genital organs for no medical reason. ${ }^{1}$ Although FGM is primarily performed in Africa, other countries such as Yemen, Iraqi Kurdistan, Indonesia and Malaysia have a high prevalence of FGM in some specific geographical areas. $^{2}$ In addition, the migration of FGM practising communities means girls worldwide are at risk. There are no health benefits to FGM and it causes serious short-term and long-term damage to physical and psychological health. ${ }^{3}$ FGM is almost always performed on children and is a violation of human rights and of the United Nation Convention of the rights of the child (Article 19). It is defined as child abuse in the UK. WHO estimates that three million girls undergo FGM each year. ${ }^{1}$ Major investment in preventative work among practising communities has led to a reduction in the incidence of FGM in some specific areas and recent Unicef data from 29 African countries demonstrates a reduction in the incidence of FGM in girls under 15 years compared with their mothers' generation. ${ }^{2}$ However such practice change is not universal and FGM still remains a major health risk for large numbers of girls from FGM practising communities. There is conflicting data about the continuation of FGM among practising communities now relocated to developed countries with some studies suggesting a decline in the practice ${ }^{4}$ while other evidence suggesting that the practice is adhered to albeit with some differences in age and type of FGM. What is clear at this point in time is that paediatricians need to be able to identify girls who have had FGM to offer appropriate health screening and, where applicable, medical treatments. It is equally important that paediatricians are equipped with the skills to identify girls at risk of FGM and take appropriate action to protect them.

\section{WHAT IS FGM?}

The first record of FGM dates from the time of the Pharaohs and it is now a deeply rooted tradition practiced by specific ethnic groups in Africa, Asia and the Middle East.

FGM is not mandated by any religious scriptures although practitioners often use religion to justify the misconception that it is necessary. Such justifications include social pressure and social acceptance, preparation of a girl for adulthood and marriage, removal of unclean body parts, to reduce libido and ensure chastity and to cement or maintain cultural identity. It is estimated that $50 \%$ of FGM is performed between the age of 0 years and 5 years with the remainder occurring between 5 years and 15 years of age. ${ }^{2}$ FGM may sometimes be performed in adult women but this is rare. Concerns have been raised that in some communities the age of FGM is being lowered in order to avoid objection or disclosure by the child although data on this is scanty. ${ }^{2}$ In traditional practice in many communities, FGM is commonly performed without anaesthetic or sterile conditions. The child may be forcibly restrained while the external genitalia are removed or damaged using a knife, scalpel or other sharp instrument. The wound is then covered and the legs bound. If the vagina has been closed, then a straw or reed is placed in the vagina to allow the vagina to heal over leaving a small opening for later micturition and menstruation.

\section{CLASSIFICATION OF FGM}

The type of FGM performed differs widely between countries and cultures. To allow more accurate description and comparison of information, WHO in 1995 classified FGM into four Types depending on the extent and amount of genital tissue removed ${ }^{5}$ (box 1). This classification was updated in 2008 and is now widely used around the world and is almost universal in the medical literature on FGM. However it is a complex and precise anatomical classification and relies on examination of the genitalia by an examiner experienced in FGM as it has been shown that genital features reported by the women do not always concur with the anatomical findings. ${ }^{6}$ Even when the examiner is experienced, the genital findings may not fit clearly into a particular type. In addition subsequent genital procedures such as childbirth or deinfibulation may render the appearances inconsistent with the original procedure. A simpler classification has been described by Unicef $^{2}$ and is now used for 
Box 1 WHO classification of female genital mutilation

Type 1: Clitoridectomy; partial or total removal of the clitoris (a small sensitive and erectile part of the female genitals) and in rare cases only the prepuce (the fold of skin surrounding the clitoris).

Type 2: Excision: partial or total removal of the clitoris and labia minora with or without removal of the labia majora (the labia are 'the lips' that surround the vagina)

Type 3: Infibulation; narrowing of the vaginal opening through the creation of a covering seal. The seal is formed by cutting and repositioning the labia minora or majora with or without removal of the clitoris.

Type 4: Other; all other harmful procedures to the genital for non-medical reasons, for example, pricking, piercing, incision, scraping and cauterising the genital area.

data collection (box 2). WHO and Unicef classifications are now in current use although some confusion may occur as they do not match exactly, Unicef Type 1 is categorised as WHO Type 4, Unicef Type 2 corresponds to WHO Type I and 2 (clitoridectomy) and Unicef Type 3 to WHO Type 3.

\section{MEDICALISATION OF FGM}

It is usually assumed that FGM is only performed by a traditional cutter or circumciser. While this is true for many countries, in some places a substantial number of procedures are performed by healthcare providers. WHO estimates that up to $17 \%$ of procedures are performed by health professionalsmost commonly nurses and midwives. Egypt is unusual as the majority of procedures are performed by doctors with $77 \%$ of mothers surveyed in Egypt reporting that FGM was performed on their daughter by a trained medical professional. ${ }^{2}$ Evidence also suggests that FGM is available-for those who can pay for it-in clinics and other medical settings with improved anaesthetic and analgesia.

It is never acceptable for doctors to offer or procure FGM and United Nations agencies have made this quite clear in two interagency statements. ${ }^{7}$ In 2010 , a statement on FGM published by the American Academy of Paediatrics in 2000 appeared to suggest that paediatricians could be complicit in arranging or even perform a 'ritual nick' as a risk reduction measure. This document was condemned worldwide and the statement was quickly formally retired and replaced. ${ }^{9}$ Of note, in a recent UK case in the Family Court concerning Leeds City Council and two children $\mathrm{B}$ and $\mathrm{G},{ }^{10}$ the judge Sir James Munby pointed out that some forms of Type IV are on any view much less invasive than male circumcision although both amount to significant harm. He pointed out the distinction between them was that while it can never be reasonable parenting to inflict any form of FGM on a child, the position is quite

\section{Box 2 Unicef classification of female genital mutilation}

Type 1: Cut, no flesh removed,

Type 2: Cut, some flesh removed,

Type 3: Sewn closed,

Type 4: Type not determined/not sure/doesn't know. different with male circumcision. It would seem that society and the law tolerate male circumcision because unlike FGM, it has a religious basis and some would suggest some health benefits.

\section{FGM AND THE LAW}

The legal status of FGM varies between countries and FGM is illegal in a growing number of countries where it is practised. FGM has been illegal in the UK since 1985 and since 2003 it has been illegal for a child to be taken out of the country for the purpose of FGM. ${ }^{11}$ However even in countries such as France where there is no specific anti-FGM legislation, practitioners of FGM can be and are prosecuted for child abuse. ${ }^{12}$ It must be also be remembered that, in contrast to the UK which has an adversarial legal system, France has a judge-led, inquisitorial legal system in which convictions are easier to secure.

\section{PREVALENCE OF FGM IN THE UK}

There is little accurate data on the prevalence of FGM in the UK. Provisional estimates based on the most recent census data suggest that in 2011 approximately 137000 women and girls in England and Wales had undergone FGM and came from countries where it is traditionally practised. ${ }^{13}$ This estimate included 103000 women aged 15-49 years, 24000 women aged 50 years or over and 10000 girls aged under 15 years. A further 60000 girls were born that year to mothers from FGM practising communities meaning a possible 70000 girls under age 15 years who have had or are at risk of FGM. Although this data gives a useful overview, these figures are thought likely to be an underestimate.

From September 2014, acute National Health Service (NHS) Trusts in England have had to return numbers of women and children seen with FGM to the Department of Health on a monthly basis. It is now mandatory for all health professionals to document in the medical notes if FGM has been found. From April 2015 data collection will also be extended to General Practice and Mental Health Trusts. Data from September to November 2014 have been published. ${ }^{14}$ In September $201478 \%$ of Trusts completed data returns and reported 467 newly diagnosed cases of FGM and 1279 already diagnosed cases. Data has not yet been released on the number of girls under 18 years included. Continuing monthly returns show figures of a similar magnitude. From April 2015 data collection will be more detailed but also linked to NHS number to prevent multiple reporting of the same patients. It is too soon as yet to comment on the figures or on the potential flaws in data collection. However it is hoped that when robust, this data collection will highlight hot spots of FGM to facilitate targeting of specialist FGM services and safeguarding work.

\section{HEALTH IMPACT OF FGM}

While many of the acute and long-term health complications of FGM in women have been well described, there are few large studies available of the incidence of such risks and the range of presentations. This is particularly so with regards to the immediate risks to children. Unfortunately most large population-based studies of FGM rely on retrospective self-report where recall may not be accurate and studies will exclude children who die as a result of FGM. Women and girls asked about FGM can be reluctant to discuss symptoms due to the sensitive nature of the topic or because of anxieties about the legal status of the practice. As well as a lack of good studies on risks of the procedure, there are no good studies on medical interventions which may address the long-term physical or psychological sequelae of FGM. 


\section{Immediate effects}

The immediate effects of FGM include haemorrhage and infection. Pain and shock are common and deaths have been reported although exact numbers are unknown for the reasons described above. Anaemia attributed to FGM has been reported in $38 \%$ of girls after FGM. $^{15}$ Infections include immediate wound infection including tetanus and gangrene. FGM has been also implicated in the transmission of bloodborne infections such as Hepatitis B and C and HIV due to the use of shared and unsterile tools. While this is probable, there are as yet no good studies to confirm this and infections such as hepatitis B and $\mathrm{HIV}$ are endemic in areas where FGM is prevalent anyway.

\section{Long-term effects}

The impact of FGM on women can be divided into obstetric, gynaecological and psychological concerns. Gynaecological conditions include painful and unsightly genital scarring as well as the formation of keloid, clitoral cysts and bladder and vulval calculi. $^{16}$ Menstrual difficulties and infertility have been reported in all Types of FGM although the underlying mechanisms of these are unclear apart from Type 3 where the vagina is narrowed. Recurrent urinary tract infections and slow urinary stream have been reported in up to $22 \%$ of women following FGM. ${ }^{17}$ There is increasing evidence that FGM damages sexual function although most studies are small with no standardised assessments or controls. A systematic review and meta-analysis found that women with FGM were more likely to report dyspareunia, absence of sexual desire and reduced sexual satisfaction. ${ }^{18}$ Stenosis of the vagina in Type 3 FGM will make sex difficult or painful while removal of sensitive sexual tissue such as the clitoris is likely to reduce sexual sensation and sexual pleasure. Recent reports claim that surgical clitoral reconstruction may restore sexual function ${ }^{19}$ but available studies of this technique are flawed with lack of long-term follow-up and psychosexual assessment. ${ }^{20}$ Mental health problems such as anxiety and depression have been linked to $\mathrm{FGM}^{21}$ and post-traumatic stress disorder has been reported as a consequence of FGM. ${ }^{22}$

It is also clear FGM has a detrimental impact on obstetric outcomes for the mother and baby. A large study published in the Lancet in 2006 of 28000 women delivering on six African countries found that women with FGM have increased risks of postpartum haemorrhage, perineal trauma and perinatal death. ${ }^{23}$ This study also described increased risks of neonatal resuscitation, low birth rate, stillbirth and early neonatal death estimating that FGM contributed to one to two extra perinatal deaths per 100 deliveries. Studies of women with FGM delivering in developed countries are much smaller and of variable quality but a meta-analysis of studies of over three million women also identified similar risks in childbirth despite obstetric interventions. ${ }^{24}$ Risks were increased with all Types of FGM but were more frequent with more extensive FGM.

\section{CLINICAL MANAGEMENT OF FGM AND SUSPECTED FGM IN CHILDREN}

\section{History and presentation}

The majority of paediatricians are unlikely to see children who are acutely unwell due to FGM. Haemorrhage and sepsis are common acute complications and can be life-threatening as demonstrated by the deaths of two babies in Paris in $1982 .{ }^{25}$ These deaths led to the first prosecution in France for FGM. However there are no reports of such acute presentations in the UK. The reasons for this are unclear and may suggest a reduction in FGM in developed countries but other possible reasons may include children being sent back to their countries of origin for FGM and only returning if well, access to medical treatment of complications within practising communities or that there is a trend towards less invasive types of FGM with less tissue damage and lower acute risk to the child. However if a paediatrician was called to see a child immediately after FGM, management would include assessment for signs of acute blood loss, sepsis and urinary retention and treatment with antibiotics, analgesia, tetanus toxoid and urinary catheterisation as required.

It is much more likely that paediatricians will be asked to see a child where FGM has been alleged by the child or family member or concerns raised by social services. In addition FGM may have been found during the investigation of other symptoms such as recurrent urinary tract infections and presentations such as when referred for a medical assessment of maltreatment. If FGM is confirmed in a child, assessment will be required of other children in the wider family including siblings and cousins for safeguarding purposes.

\section{Genital examination}

It is assumed the FGM will always be obvious on genital inspection but this is not the case. While Type 3 FGM where the vagina is sealed is usually reasonably obvious, other Types of FGM can be more difficult to diagnose confidently. This is particularly true for Type 4 FGM (Unicef Type 1). Type 4 FGM may comprise a prick or small scratch on or adjacent to the clitoris. This may heal completely leaving either no scar or a small scar which is difficult to detect especially if seen years after the event as the genitalia will change with normal growth and development. Tiny irregularities in the skin of the vulva or clitoris can be due to congenital variation. The situation is made more difficult because health professionals who specialise in FGM are usually midwives or gynaecologists. ${ }^{10}$ They will be familiar with the findings in adult women with Type 3 FGM but will not be familiar with the range of normal genital findings in children. Conversely, paediatricians working in safeguarding will have extensive experience in genital examination in children and tend to concentrate on the hymenal and anal findings. They may not even examine the clitoris in detail unless specifically looking for FGM and may have very little prior experience of examining children with FGM. ${ }^{10}$

As always, genital examination of children for FGM should be performed in a sensitive and gentle manner and in an age-appropriate setting. The examiner should be trained in the genital assessment of children and the range of FGM findings. Use of the colposcope is essential to allow detection of Type 4 FGM and to take the DVD for peer review or to seek a second opinion from an expert. In addition photo documentation for all Types of FGM will be required in the case of any subsequent legal proceedings. It is thought that in many cases seen within the UK, children will have had FGM in a country where FGM is not illegal prior to entering the UK for the first time. This means criminal proceedings are not possible if the FGM was done prior to 2003. Attention must still be given to the wider family in order to assess the risk and to ensure the current law is known. The family should be given the Home Office FGM health passport for any planned trips abroad. ${ }^{26}$

\section{Management of FGM}

General assessment of the child's overall health with relation to complications of FGM should be made. Screening for bloodborne viruses should be offered. If the child has Type 3 FGM, then a deinfibulation procedure to open the vaginal scar tissue can be offered. Deinfibulation is a minor surgical procedure to 
divide any scar tissue which obscures the vaginal introitus. This procedure is sometimes erroneously termed a 'reversal' of FGM. This term is incorrect as deinfibulation cannot restore genital tissue which has been removed by FGM. Deinfibulation procedures are usually performed under local anaesthetic in adult women but in children a brief general anaesthetic would be more appropriate. Other types of FGM do not need surgical treatments and as yet there is no evidence as to the benefit of clitoral surgery. The psychological impact on a child may be severe and flashbacks and nightmares have been reported. Input from a child psychologist with experience of working with children with FGM and their families should be available. There are several excellent patient peer support groups which support the whole family and details should be available in clinics. ${ }^{27}$

\section{Safeguarding}

If a child is confirmed to have FGM then children's social services should be informed if not already involved and local and national guidelines followed. ${ }^{28}$ This is not a new duty as it is already a professional requirement to report any suspected or alleged child maltreatment/abuse which includes FGM as explained earlier. ${ }^{29}$ It is the responsibility of all health professionals to notify social services and in the case of FGM this should be done urgently given the imperative to protect others and secure a conviction in the UK. Social care will follow their local procedures which in the first instance will be an urgent strategy discussion with the police. The police will act accordingly depending on whether a crime has been committed under the terms of the FGM Act, that is, FGM has been performed in the UK since 1998 or that a British girl has been taken abroad for FGM since 2003. Paediatricians must work closely with the multiagency team and examine any girls thought to be at risk or to have had FGM, such as other family members particularly younger sisters or other young female relatives. If FGM is not confirmed in younger siblings, parents should be made aware of the legal status of FGM and the criminal penalties for performing or procuring FGM for their daughter. There is no routine surveillance of such girls in the UK but the information that they are at risk of FGM should be shared with the child's health professionals which will include the general practitioner and health visitor or school nurse depending on the age of the child.

There has been a recent Home Office public consultation ongoing on whether it should become mandatory to report all cases of FGM to the police and what sanctions should apply to health professionals and others who fail to do so. However, if professional practice is followed, all cases of FGM in children must in any event be reported as in any child abuse. There is no evidence that mandatory reporting improves the detection of child abuse. The Royal College of Paediatrics and Child Health (RCPCH) does not believe that mandatory reporting by medical professionals should be introduced. ${ }^{30}$ The RCPCH is concerned about the introduction of mandatory reporting with sanctions before the introduction of adequate educational resources to support health professionals. It also expresses particular concern about the singling out of FGM as 'an extremely harmful form of child abuse' reinforcing an unhelpful hierarchy of abuse. ${ }^{30}$ Despite these concerns, the home office has concluded that all under-18s with FGM should be referred directly to the police and this has been added to the Serious Crime Bill currently going through Parliament.

\section{TRAINING FOR PAEDIATRICIANS}

$\mathrm{RCPCH}$ is committed to supporting the training of all paediatricians in the management of children with FGM. To that effect
$\mathrm{RCPCH}$ intercollegiate guidance for training health professionals recommends that FGM should be included in all training from level 1 to level $6^{31}$ In addition there is an e-learning FGM lecture by the author DH that can be accessed with a login. ${ }^{32}$

Health Education England have recently launched an e-learning module on FGM. ${ }^{33}$ This is an open access introductory module for all health professionals. Additional more detailed modules are under preparation and are due for release later in 2015. These modules include training on how to talk to patients about FGM, safeguarding and obstetric and gynaecological management. Health professionals seeking more guidance can also access Multiagency Practice Guidelines ${ }^{28}$ and the NHS Choices website. ${ }^{34}$

\section{CONCLUSION}

While accurate data on FGM in children in the UK is lacking, provisional data estimates that 70000 girls are at risk. Paediatricians need to be familiar with the health implications and physical findings in children with FGM. They must also be aware of the legal status of FGM and their own responsibilities with regards to recording and reporting FGM. Paediatricians working within safeguarding clinics are likely to be increasingly called upon to assess whether or not a child has had FGM. Confirmation of FGM in young children may be difficult. Genital findings may be subtle and this may be due to the performance of less invasive types of FGM in girls at a younger age. Further data on all aspects of FGM in children is urgently needed.

\section{Competing interests None.}

Patient consent Obtained.

Provenance and peer review Commissioned; externally peer reviewed.

\section{REFERENCES}

1 World Health Organization (WHO). Female genital mutilation. Fact sheet No 241, Updated Feb 2014. http://www.who.int/mediacentre/factsheets/fs241/en/

2 UNICEF Female Genital Mutilation/ Cutting A statistical overview and exploration of the dynamics of change. July 2013 (http://www.unicef.org) http://www.unicef.org/ media/files/FGCM_Lo_res.pdf

3 WHO. A Systematic Review of the Health Complications of Female Genital Mutilation, including Sequelae in Childbirth. WHO/FCH/WMH/00.2. 2000. http:// www.who.int/gender/other health/systreviewFGM.pdf?ua=1

4 Gele AA, Johansen EB, Sundby J. When female circumcision comes to the West: attitudes toward the practice among Somali immigrants in Oslo. BMC Public Health 2012;12:697

5 World Health Organization. Female genital mutilation: report of a WHO technical working group. Geneva: Division of Family Health, 17-19 July 1995.

6 Elmusharaf S, Elhadi N, Almroth L. Reliability of self reported forms of female genital mutilation and WHO classification: cross sectional study. BMJ 2006;333:124.

7 Eliminating female genital mutilation: An interagency statement. $2008 \mathrm{OHCHR}$ UNAIDS, UNDP, UNECA, UNESCO, UNFPA, UNHCR, UNICEF, UNIFEM, WHO. http:// www.who.int/reproductivehealth/publications/fgm/rhr_10_9/en/

8 Global strategy to stop health-care providers from performing female genital mutilation. 2010 UNFPA, UNHCR, UNICEF, UNIFEM, WHO, FIGO, ICN, MWIA, WCPA, WMA. http://www.who.int/reproductivehealth/publications/fgm/rhr_10_9/en/

9 American Academy of Paediatrics Policy Statement-Ritual Genital Cutting of Female Minors doi: 10.1542/peds.2010-0187).

10 Leeds city council B and G Case No: LJ13C00295. http://www.judiciary.gov.uk/ wp-content/uploads/2015/01/BandG_2_.pdf

11 Female Genital mutilation Act 2003. http://www.legislation.gov.uk

12 Current situation of female genital mutilation in France European Institute for Gender Equality. 2012 eige.europa.eu.

13 Macfarlane A, Dorkenoo E. Female Genital Mutilation in England \& Wales. Updated statistical estimates of the numbers of affected women living in England and Wales and girls at risk 2014. Equality Now and City University London. http://www. equalitynow.org

14 Female genital Mutilation Data Prevalence Set. ewww.hscic.gov.uk/FGM

15 Kaplan A, Hechavarría S, Martín M, et al. Health consequences of female genital mutilation/cutting in the Gambia, evidence into action. Reprod Health 2011;8:26. 
16 Reisel D, Creighton SM. Long term health consequences of Female Genital Mutilation (FGM). Maturitas, 2015.

17 Amin MM, Rasheed S, Salem E. Lower urinary tract symptoms following Female Genital Mutilation. Int J Obstet Gynecol 2013;123:21-3.

18 Berg RC, Denison E, Fretheim A. Psychological, social and sexual consequences of female genital mutilation/cutting (FGM/C): a systematic review of quantitative studies. Report from Norwegian Knowledge Centre for the Health Services, 2013 No. 10.

19 Foldes $P, C$ Cuzinb $B$, Andro $A$. Reconstructive surgery after female genital mutilation: a prospective cohort study. Lancet 2012;380:134-41.

20 Creighton S, Bewley S, Liao LM. Reconstructive surgery after female genital mutilation. Lancet 2012;380:1469. Author reply.

21 Vloesberg E, van den Kwaak A, Knipscheer J, et al. Coping and chronic psychosocial consequences of female genital mutilation in the Netherlands. Ethn Health 2012;17:677-95.

22 Behrendt A, Moritz S. Post-traumatic stress disorder and memory problems after female genital mutilation. Am J Psychiatry 2005;162:1000-2.

23 WHO Study Group on Female Genital Mutilation and Obstetric Outcome. Female genital mutilation and obstetric outcome: WHO collaborative prospective study in six African countries. Lancet 2006;367:1835-41.
24 Berg RC, Underland V. The obstetric consequences of female genital mutilation/cutting: a systematic review and meta-analysis. Obstet Gynecol Int 2013;2013:496564.

25 Gallard C. Education and debate: female genital mutilation in France. BMJ 1995;310:1592-3.

26 https://www.gov.uk/government/uploads/system/uploads/attachment_data/file/ 378132/FGMstatementNov14.pdf

27 http://www.forwarduk.org

28 Multi-agency Practice Guidelines: Female Genital Mutilation. http://www.gov.uk Updated 2014.

29 General Medical Council Protecting children and young people: The responsibilities of all doctors. 2012. http://www.gmc-

30 Consultation response submitted by the Royal College of Paediatrics and Child Health. http://www.rcpch.ac.uk/system/files/protected/consultation/RCPCH

31 Safeguarding Children and Young people: roles and competences for health care staff, Intercollegiate Document. Royal College of Paediatrics and Child Health, 2014.

32 Paediatrics Today: Female Genital Mutilation (FGM). RCPCH Compass. 2014. http:/l rcpch.learningpool.com/course/view.php?id=19

33 Health Education England. http://www.e-lfh.org.uk

34 Female Genital Mutilation: NHS Choices. http://www.nhs.uk/conditions/ female-genital-mutilation 